\title{
Compact Broadband Monopole Antenna for C Band Applications
}

\author{
Parul Pathak $* 1$, P. K. Singhal ${ }^{2}$ \\ ${ }^{1}$ Madhav Institute of Technology and Science \\ *corresponding author, E-mail: parul.pathak5egmail.com
}

\begin{abstract}
This paper reports a new design of broadband monopole patch antenna. The proposed antenna possess corner truncated rectangular patch with slits and defected ground structure, these modifications considerably improves the measured impedance bandwidth to $41.29 \%$ over a wideband $(5.1-7.59 \mathrm{GHz})$ while the simulated impedance bandwidth is $46.77 \%$. The design is appropriate for wireless communication including WLAN IEEE $802.11 \mathrm{~g} / \mathrm{a}$ (5.15$5.35 \mathrm{GHz}$ and 5.725-5.825 GHz) and $\mathrm{C}$ Band (4-8 GHz) applications. An antenna prototype is fabricated using FR-4 with an electrical permittivity of 4.4. Experimental and numerical simulations of antenna's radiation characteristics are also reported and exhibits good concurrence.
\end{abstract}

\section{Introduction}

Microstrip patch antennas are favoured over other antenna configurations due to its features appropriate primarily for applications operative in higher frequency range including $\mathrm{RF}$ and microwave region. In its modest form the microstrip antennas has patch positioned on the top with negligible thickness as compared to dielectric substrate placed in the middle, followed by ground plane at the bottom. Generally same conductor is used for patch and the ground like gold or copper and a low tangent loss dielectric is used for substrate. Although microstrip antennas are considered to be low profile but their ability to radiate efficiently is a very important characteristic. The radiations occur in a microstrip patch antenna due to fringing fields present at the edges [1]. The conventional microstrip antenna usually resonates at a single frequency and its performance can be noticeably enhanced when its shape and dimensions are optimized. The use of microstrip patch antennas in wireless devices is very common now a days and the capability of modified patch antennas to operate in broadband or multiband has prompted researchers to work extensively in this area. The various applications of microstrip antenna includes wireless local area networks (WLANs), world-wide interoperability for microwave access (WiMAX), Bluetooth, Wi-Fi, cellular phones etc. [2].

Due to rapid growth of microwave and wireless communication applications, the role of small-sized devices such as compact antennas is increasing day by day. For this purpose, compact antennas with broadband characteristics are in great demand [3-4]. In order to have better antenna performance, antennas with low dielectric constant and larger thickness are preferred, as they are capable of providing larger bandwidth, good efficiency and better radiation characteristics. However, there exists a trade-off among the antenna size, antenna performance and the cost [5-6]. In past various methods are used to enhance the bandwidth, improve the radiation characteristics of antennas and some of the techniques include use of various impedance matching and feeding techniques [7-13]. Among the various feeding techniques, the microstripline feeding mechanism has many advantages over other feed line structures, such as low radiation leakage, low dispersion, lesser complexity and the ability to effectively control the characteristic impedance, and the ease of integration with active devices [5-6]. The various techniques including use of multiple resonators, etching slots in the antenna geometry, stacked patches, shorting pin, introduction of air gap for obtaining improved radiation performance have been also reported in past [14-18].

In order to protect the microstrip patch antennas from the adverse effects of dielectric and surface wave losses, use of defected ground structures is one of the methods to mitigate such kinds of losses. Recently, in many patch antennas applications, defected ground structures are suggested. Defected ground is realized by etching a defect in the ground plane of planar circuits and antennas. The advantage of using defected ground is that spurious surface wave excitation is less and even the low dielectric substrate does not support higher order mode [19-20]. Also benefits of defected ground is reduction of size and excitations of additional resonance bands. In recent past, many types of antenna designs for WLAN/WiMAX applications have been described in the literature. A monopole antenna with dual-band operation is described in this paper [21]. The antenna structure has ground plane which is defected with three rectangular slots and modified U-shaped rectangular patch. By introducing defects in the ground plane the size of the antenna is reduced by nearly $12 \%$. A reduced size circular patch antenna with metamaterial has been reported in this paper [22]. By using the complementary split ring resonator in the ground, the size is reduced to $64 \%$. A compact antenna with defected ground for triple band operation is investigated in this work. The antenna is suitable for WLAN/WiMAX applications. The designs consists of two F-shape slots in the patch and circular and rectangular strips at the ground [23].

In this paper, analysis of the performance of monopole antenna for $\mathrm{C}$ band applications is carried out. The antenna 
has a compact size of $40 \times 40 \times 1.59 \mathrm{~mm}^{3}$ and provides an impedance bandwidth of $41.29 \%$. Parametric analysis is done in and the performance of antenna is assessed with that of a conventional patch. The properties like reflection coefficient, bandwidth, gain, radiation patterns, and voltage standing wave ratio (VSWR) are simulated and verified experimentally for the proposed geometry.

\section{Antenna design specification and Parametric Analysis}

Among the conventional geometries, rectangular shape of the patch is most common geometry. Due to larger in shape, rectangular patches provide broadest bandwidth [4][24]. According to [25-26], partial ground plane leads to wide impedance bandwidth. Hence, the present work started by considering a rectangular patch with a partial ground plane as shown in Figure 1a and $1 \mathrm{~b}$.

The initial design consists of rectangular patch of size $20 \times 15$ $\mathrm{mm}$, with partial ground having dimensions of $40 \times 15 \mathrm{~mm}$ as shown in Figure 1a \& 1b. The width of the microstripline is of $2.2 \mathrm{~mm}$, and $15 \mathrm{~mm}$ long. Dielectric substrate (FR4 epoxy) with relative dielectric constant of 4.4, loss tangent of 0.025 , and thickness of $1.59 \mathrm{~mm}$ has been used. The structured antenna design is having single-layer metallic structure on both side of the substrate (top as well as bottom), on one side there is rectangular patch and other has ground. From the current distribution of the conventional geometry Figure 1c, it is observed that the current concentration remains on the feed line and lower portion of radiating patch. The patch has not considerably affected the performance of the geometry. In next step slots are etched to perturb the current distribution and excite other modes overlapping with each other to achieve broad bandwidth.

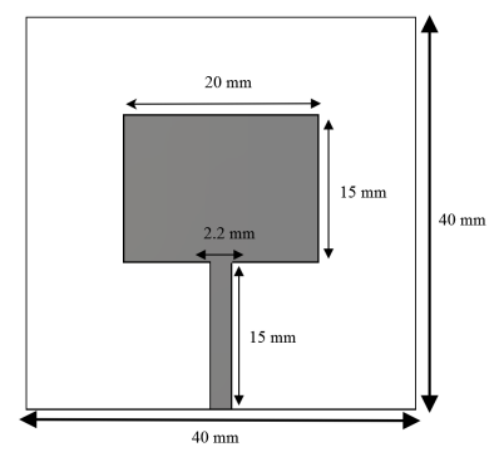

Figure 1a: Top view rectangular patch antenna

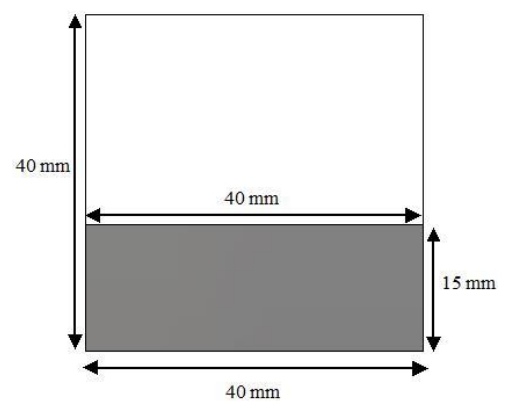

Figure 1b: Back view of rectangular patch antenna

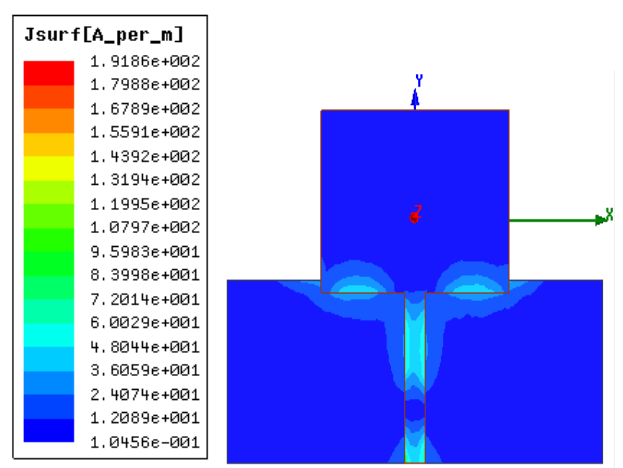

Figure 1c: Simulated current distributions of conventional geometry

The dimensions of the patch are retained identical as considered for conventional antenna. Now, with the introduction of defected ground and slots onto the patch, the simulated resonant frequencies, gain, bandwidth of modified structure is examined and the variation of size (length and widths) of both rectangular slots (slot A, slot B) with their simulated results are depicted in Table 1-5.

Optimization has been done in step by step manner. The first step is optimizing the dimensions of the slot A and dimensions of slot B is kept fixed. The second step is optimizing the slot B keeping dimensions of slot A constant. In this way the geometry is optimized to get the desired performance.

Table 1: Effect of variation of the length of slot (A) on radiation parameters

\begin{tabular}{lllll}
\hline $\begin{array}{l}\text { Length } \\
(\mathrm{mm})\end{array}$ & $\begin{array}{l}\text { Resonant } \\
\text { frequency } \\
(\mathrm{GHz})\end{array}$ & $\begin{array}{l}\text { Return } \\
\text { loss } \\
(\mathrm{dB})\end{array}$ & $\begin{array}{l}\text { Bandwidth } \\
(\%)\end{array}$ & $\begin{array}{l}\text { Gain } \\
(\mathrm{dBi})\end{array}$ \\
\hline 10 & 5.71 & -34.5 & 39.8 & 2.1 \\
\hline 11 & 5.71 & -34.9 & 38.5 & 2.2 \\
\hline 12 & 5.43 & -27.02 & 46.77 & 2.82 \\
\hline 13 & 5.38 & -20.77 & 44.60 & 2.5 \\
\hline 14 & 5.38 & -20.16 & 39.25 & 2.12 \\
\hline
\end{tabular}

Table 2: Effect of variation of the width of slot (A) on radiation parameters

\begin{tabular}{ccccc}
\hline $\begin{array}{c}\text { Width } \\
(\mathrm{mm})\end{array}$ & $\begin{array}{c}\text { Resonant } \\
\text { frequency } \\
(\mathrm{GHz})\end{array}$ & $\begin{array}{c}\text { Return } \\
\text { loss } \\
(\mathrm{dB})\end{array}$ & $\begin{array}{c}\text { Band } \\
\text { width } \\
(\%)\end{array}$ & $\begin{array}{c}\text { Gain } \\
(\mathrm{dBi})\end{array}$ \\
\hline 0.5 & 5.62 & -18.3 & 25.5 & 2.77 \\
\hline 1 & 5.43 & -27.01 & 46.77 & 2.82 \\
\hline 2 & 5.69 & -20.3 & 30.7 & 2.02 \\
\hline 2.5 & 5.72 & -25.34 & 29.4 & 2.22 \\
\hline 3 & 5.71 & -20.6 & 30.23 & 2.11 \\
\hline
\end{tabular}


Table 3: Effect of variation of the length of slot (B) on radiation parameters

\begin{tabular}{ccccc}
\hline $\begin{array}{c}\text { Length } \\
(\mathrm{mm})\end{array}$ & $\begin{array}{c}\text { Resonant } \\
\text { frequency(GHz) }\end{array}$ & $\begin{array}{c}\text { Return } \\
\text { loss } \\
(\mathrm{dB})\end{array}$ & $\begin{array}{c}\text { Band } \\
\text { width } \\
(\%)\end{array}$ & $\begin{array}{c}\text { Gain } \\
(\mathrm{dBi})\end{array}$ \\
\hline 10 & 3.48 & -21.70 & 35.52 & 2.02 \\
\hline 12 & 5.43 & -27.02 & 46.77 & 2.82 \\
\hline 13 & 3.44 & -25.03 & 34.63 & 2.80 \\
\hline 14 & 3.49 & -17.04 & 34.81 & 2.27 \\
\hline 11 & 3.46 & -15.23 & 33.89 & 2.05 \\
\hline
\end{tabular}

Table 4: Effect of variation of the width of slot (B) on radiation parameters

\begin{tabular}{cccccc}
\hline $\begin{array}{c}\text { Leng } \\
\text { th } \\
(\mathrm{mm})\end{array}$ & $\begin{array}{c}\text { Widt } \\
\mathrm{h} \\
(\mathrm{mm})\end{array}$ & $\begin{array}{c}\text { Resonant } \\
\text { frequency } \\
(\mathrm{GHz})\end{array}$ & $\begin{array}{c}\text { Retur } \\
\text { n loss } \\
(\mathrm{dB})\end{array}$ & $\begin{array}{c}\text { Bandwid } \\
\text { th } \\
(\%)\end{array}$ & $\begin{array}{c}\text { Gain } \\
(\mathrm{dBi})\end{array}$ \\
\hline 12 & 2.5 & 5.48 & -21.70 & 25.52 & 2.02 \\
\hline 12 & 2.1 & 5.55 & -33.27 & 38.32 & 2.82 \\
\hline 12 & 2.0 & 5.44 & -25.03 & 34.63 & 2.70 \\
\hline 12 & 1.5 & 5.59 & -27.04 & 27.71 & 2.26 \\
\hline 12 & 1 & 5.43 & -27.02 & 46.77 & 2.82 \\
\hline
\end{tabular}

Table 5: Final specifications of the proposed geometry

\begin{tabular}{cccc}
\hline \multicolumn{2}{c}{ Slot A } & \multicolumn{2}{c}{ Slot B } \\
\hline Length & width & Length & width \\
\hline $12 \mathrm{~mm}$ & $1 \mathrm{~mm}$ & $12 \mathrm{~mm}$ & $1 \mathrm{~mm}$ \\
\hline
\end{tabular}

The values of parameters like dimension and location of the slots in patch and ground plane in geometry are chosen after performing parametric study for the condition of $\mathrm{S}_{11}<10 \mathrm{~dB}$ and in range of frequencies 4-8 $\mathrm{GHz}$. Based on the parametric analysis, described in Table 1 to 5 , the best results were obtained at length= $12 \mathrm{~mm}$, width $=1 \mathrm{~mm}$ for the slots.

The top view of the proposed antenna is depicted in Figure $2 \mathrm{a}$ having patch with two rectangular slots (slot A slot B) etched off, with dimensions of $12 \times 1 \mathrm{~mm}$ each, in order to enhance the bandwidth and gain of the antenna geometry and Figure $2 \mathrm{~b}$ depicts the defected ground. The antenna size is kept compact enough to fit the portable devices such that the antenna can perform well for higher frequencies and wireless applications.

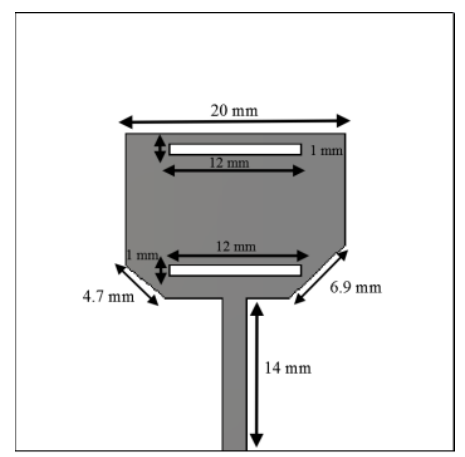

Figure 2a: Top view of proposed antenna

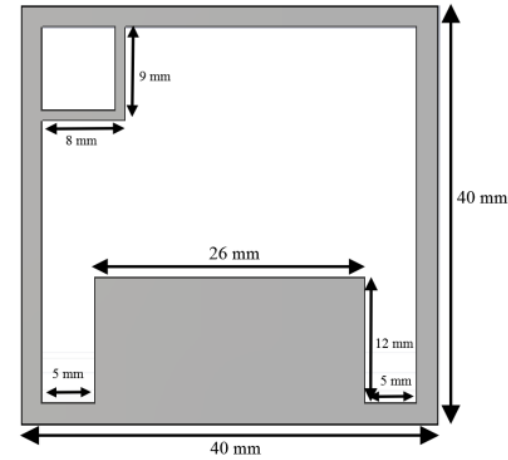

Figure 2b: Bottom view of proposed antenna

\section{Results and Discussion}

The conventional microstripline-fed antenna has a small impedance bandwidth and gain. This proposed antenna with defects in the ground as compared to conventional antenna achieves a significant simulated impedance bandwidth of $46.77 \%$ ranging from 4.89 to $7.43 \mathrm{GHz}$ with central frequency at $5.43 \mathrm{GHz}$. The compact size and achieved broadband from 4.89 to $7.43 \mathrm{GHz}$ makes this antenna a good candidate for wideband applications and futuristic communication system. With proposed introductions, it is observed that the performance of antenna is significantly improved. The comparison of variation in reflection coefficient as a function of frequency for proposed and conventional geometry is shown in figure. 3. It can be observed that proposed antenna is now resonating at frequencies $5.43 \mathrm{GHz}$ which shows a shift of resonant frequency from $8.07 \mathrm{GHz}$ of the conventional geometry. With the introduction of defected ground and slots on the patch a desired shift in resonant frequency is observed and bandwidth enhancement of $46.77 \%(4.89-7.43 \mathrm{GHz})$ is also achieved, which is nearly 5 times the bandwidth than that for previously described conventional antenna i.e. $9.29 \%$.

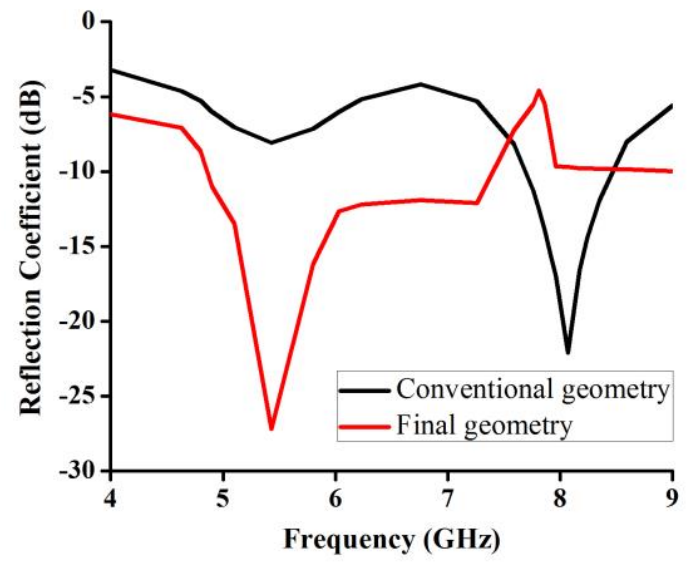

Figure 3: Comparison of simulated return loss $(\mathrm{dB})$ of conventional and proposed geometry as a function of frequency $(\mathrm{GHz})$.

The simulated values of gain and VSWR for final and conventional geometry are depicted in figure $4 \mathrm{a}$ and $\mathrm{b}$ in 
which it is showing a gain of $2.82 \mathrm{~dB}$ and VSWR of 1.01 at resonant frequency of $5.43 \mathrm{GHz}$. From frequency 5.76 to $6.78 \mathrm{GHz}$ a nearly constant gain of around $4 \mathrm{~dB}$ is seen which is quite higher than seen for conventional geometry. A good agreement of VSWR is also seen in the whole operating frequency band of $4.89-7.43 \mathrm{GHz}$ which is less than 1.5, ensuring extremely good matching and performance over the whole band.

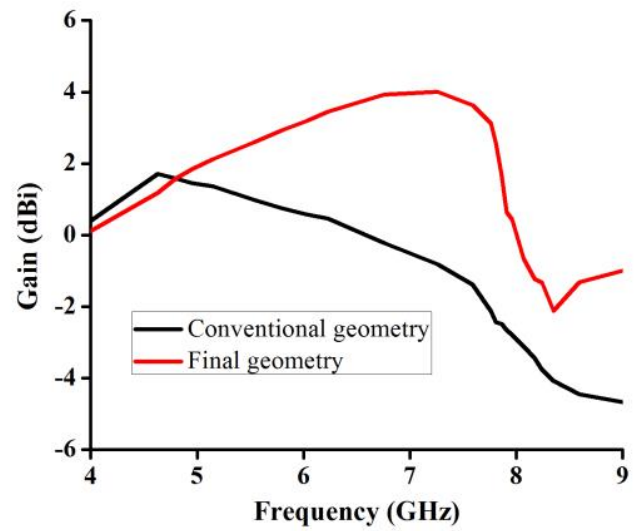

Figure 4a: Comparison of gain $(\mathrm{dB})$ of conventional and proposed geometry as a function of frequency

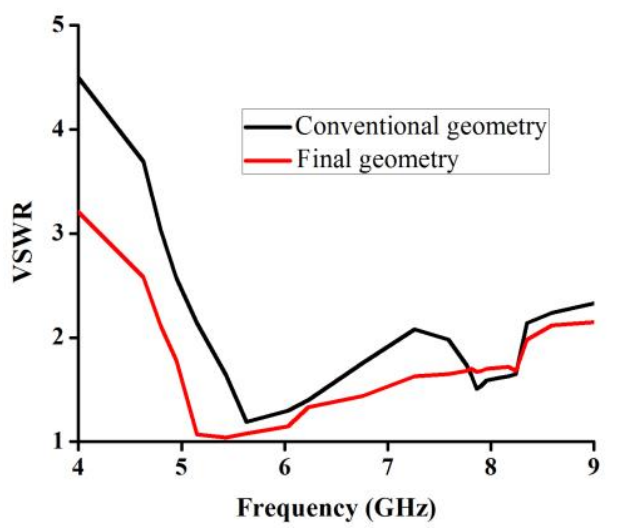

Figure 4b: Comparison of VSWR curve (dB) of conventional and proposed geometry as a function of frequency $(\mathrm{GHz})$.

The radiation patterns of the proposed and conventional antenna at resonant frequencies are depicted in figure $5 \mathrm{a}$ and $b$. These plots corroborate the broadside directive radiation pattern of the proposed antenna.
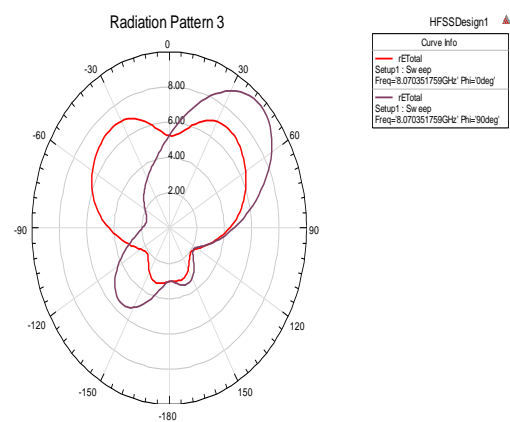

Figure 5a: Variation of $\mathrm{E}$ and $\mathrm{H}$ plane elevation patterns for Conventional geometry
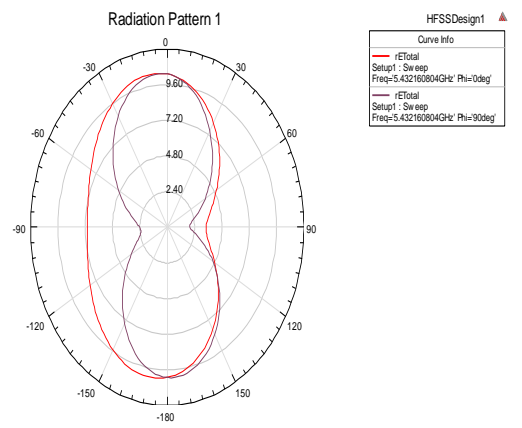

Figure 5b: Variation of $\mathrm{E}$ and $\mathrm{H}$ plane elevation for proposed geometry at resonant frequency.

The measured and the simulated results for return loss and VSWR are also in good agreement by visually comparing the data sets as shown in figure 6 , however a slight reduction in the measured impedance bandwidth (41.29\%) is found. For visually complex data Feature Selective Validation (FSV) method can be employed. The structure of the FSV involves reading the two data files to be compared and interpolating them over the common window (often common frequency range) so that the data-points to be compared are coincident [27-28]. The fabricated prototype of proposed geometry is shown in figure 7 .

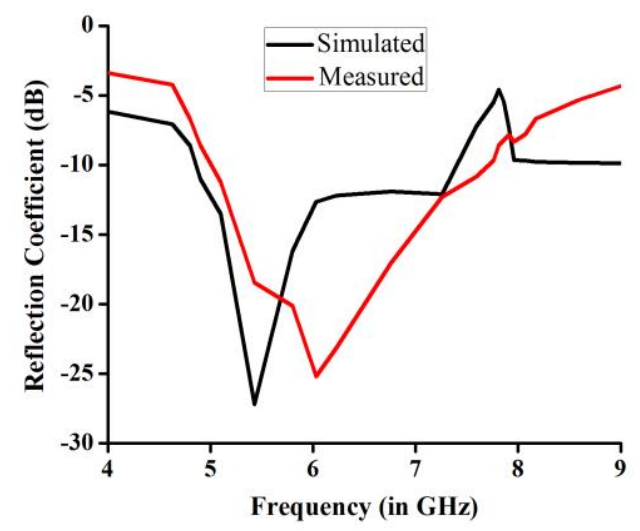

Figure 6a: Measured and simulated results of reflection coefficient $(\mathrm{dB})$ as a function of frequency $(\mathrm{GHz})$ of proposed geometry 


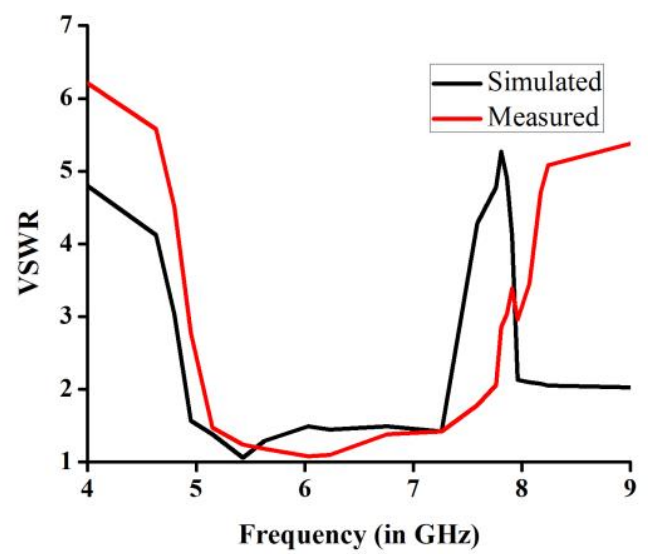

Figure $6 \mathrm{~b}$. Measured and simulated results of VSWR (dB) as a function of frequency $(\mathrm{GHz})$ of proposed geometry.

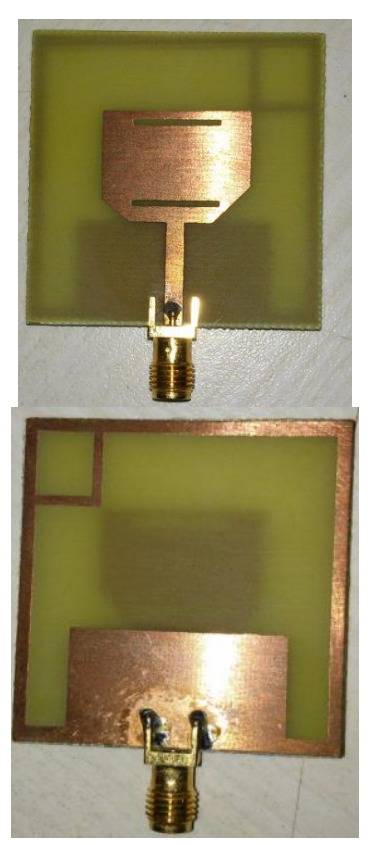

Figure 7: Fabricated prototype of proposed geometry.

The current distribution of proposed antenna is also analysed, as shown in figure 8 . The density of current is high along central metallic strip of the strip line feed along periphery of the slots. This clearly explains that the current distribution is largely effected by the dimension and position of the slots.

Although the antenna improvement is under process, its simulation results are encouraging. The proposed antenna design can be further modified for its use as flexible antennas. Flexible antennas are robust light weight antennas which are withstanding mechanical strain up to a certain extent. The materials are selected according to the design requirements, including the conductive and substrate material. These antennas can be used in flexible RFID tags, E -Textiles, Military, Air Planes, Medicine [29-30].

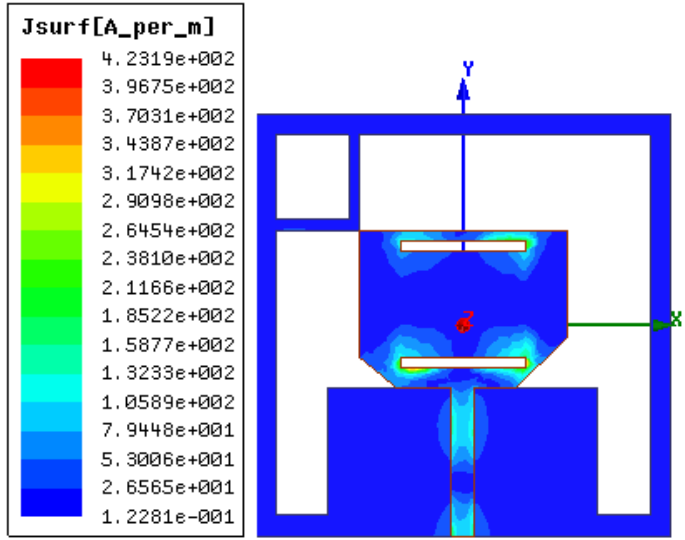

Figure 8: Simulated current distributions of Proposed Geometry

\section{Conclusion}

Microstripline-fed rectangular patch antenna has been designed, characterized, parametrically analyzed and fabricated to obtain high bandwidth with defected ground for modern communication systems. The measured impedance bandwidth offered by antenna resonating at a frequency of $6.03 \mathrm{GHz}$ is $41.29 \%$ which is well tuned to the simulation results. The gain and VSWR of this antenna are improved to great extent, but still it can be improved by choosing better substrate material. The wideband is realized by optimizing the position and dimensions of the rectangular slots in the patch and the ground plane. Gain enhancement is achieved by implementing defected ground optimization in conventional geometry. The antenna design is simple and can be easily mounted and packaged with other microwave devices and circuits. The radiation pattern is also examined to be stable over the entire bandwidth range of proposed antenna. The proposed antenna structure can be used for futuristic wireless systems.

\section{References}

[1] G.A. Deshamps, "Microstrip Microwave Antennas," Third USAF Symposium on Antennas, 1953.

[2] W. Stutzman and G. Thiele, Antenna Theory and Design, New York, John Wiley \& Sons, Inc., 1998.

[3] C. A. Balanis, Antenna Theory Analysis and Design, Third Edition, March, Wiley Publication, 2005.

[4] J R James and P S Hall, Handbook of Microstrip Antennas, Peter Peregrinus Ltd, 1989.

[5] D. M Pozar, "Microstrip Antennas, Proc. IEEE, Vol. 80, pp. 79-91, 1989.

[6] R. Garg, P. Bhartia, I. J. Bhal, A. Ittipiboon, Microstrip Antenna Design Book, Artech House Publishers, 2001.

[7] H. M. Chen, Y. K. Wang and S.C. Pan, Microstrip-Fed Circularly Polarized Square-Ring Patch Antenna for GPS Applications, IEEE Transactions on Antennas and Propagation, p. 4-7, 2009.

[8] J. Y, Jan, K. Y. Chiu, J. H. Duan, L. C Wang, C. Y. Pan and H. M. Chen, Compact Microstrip-Line-Fed Broadband Slot Antenna, IEEE Antennas and 
Propagation Society International Symposium (APSURSI), Vol. 3, p. 1-4., 2010.

[9] M. Bugaj, R. Przesmycki, L. Nowosielski and K. Piwowarczyk, Analysis Different Methods of Microstrip Antennas Feeding for their Electrical Parameters, Proc. Progress in Electromagnetics Research Letters (PIER), pp. 62-66. 2012.

[10]D. Mitra, D. Das, S. R. B. Chaudhuri, Bandwidth Enhancement of Microstrip Line and CPW-Fed Asymmetrical Slot Antennas, Progress in Electromagnetics Research Letters (PIER), vol. 32, pp. 69- 79, 2012.

[11] M. D. Sharma, A. Katariya and R. S. Meena, Broad Band Aperture Coupled Microstrip Antenna with Dual Feed and Three Feed Technique, IEEE International Conference on Communication Systems and Network Technologies (CSNT), pp. 62-65, 2012.

[12] A. Mandal, A. Ghosal, A. Majumdar, A. Ghosh, A. Das, and S. K. Das, Analysis of Feeding Techniques of Rectangular Microstrip Antenna, IEEE International Conference Signal Processing, Communication and Computing (ICSPCC),_vol. 9, pp. 26-31, 2012.

[13] M. D. Sharma, A. Katariya, and A. K. Pandit, "'Design and Simulation of Broad Band Aperture Coupled Microstrip Antenna, Fourth International Conference on Computational Intelligence and Communication Networks (CICN), pp. 32-36, 2012.

[14] M. L. Xiaodong, Yang, and A. Xiaoming, Compact Notch Band Ultra-wideband Antenna Using a pair of IShaped Parasitic Elements, Global Symposium on Millimeter Waves (GSMM), pp. 151-154, 2012.

[15] L. Jain, R. Singh, S. Rawat and K. Ray, Miniaturized meandered and stacked MSA using accelerated design strategy for biomedical applications, at $5^{\text {th }}$ International Conference on Soft Computing for Problem Solving, pp. 721-728, 2015.

[16] M. Karamanoglu, M. Abbak and S. Şimşek, "A Planar Ultra-Wideband Monopole Antenna with Half-Circular Parasitic Patches, $13^{\text {th }}$ Mediterranean Microwave Symposium, pp.1-4, 2013.

[17] A. Agrawal, P. K Singhal, and A. Jain, Design and optimization of a microstrip patch antenna for increased bandwidth, International Journal of Microwave and Wireless Technologies, pp. 529-535, 2013.

[18] S. Rawat, and K. K. Sharma, Stacked Configuration of Rectangular and Hexagonal Patches with Shorting pin for Circularly Polarized Wideband Performance, Central European Journal of Engineering, vol. 4, pp. 20-26, 2013.

[19] S. Rawat, and K. K. Sharma, A Compact broadband microstrip patch antenna with defected ground structure for C-Band Applications, Central European Journal of Engineering, vol. 4, pp. 287-292, 2014.

[20] S. Rawat, and K. K. Sharma, Annular Ring Microstrip Patch Antenna with Finite Ground Plane for UltraWideband Applications, International Journal of Microwave and Wireless Technologies, pp. 179-184, 2015.
[21] S. Kumar and R. Tomar, A Dual-Band Compact Printed Monopole Antenna using Multiple Rectangle-Shaped Defected Ground Structures and Cross-Shaped Feed Line, Microwave and Optical Technology Letters, vol. 57, no. 8, pp. 1810-1813, 2015.

[22]F. Raval, Y.P. Kosta and H. Joshi, Reduced size patch antenna using complementary split ring resonator as defected ground plane, International Journal of Electronics and Communications, pp. 1126-1133, 2015.

[23] A. K. Gautam, L. Kumar, B. K. Kanaujia, and K. Rambabu, Design of Compact F-Shaped Slot TripleBand Antenna for WLAN/WiMAX Applications, IEEE Transactions on Antennas and Propagation, vol. 64, no. 3, pp. 1101-1104, 2016.

[24] I. J. Bahl and P. Bhartia, Microstrip Antennas, Dedham, MA: Artech House, 1980.

[25] J. S. Khinda, M. R. Tripathy, and D. Gambhir, Improvement in Depth of Return Loss of Microstrip Antenna for S-Band Applications, Journal of Circuits, Systems, and Computers, 2018.

[26] M. R. Zaman, R. Azim, N. Misran, M. F. Asillam, and T. Islam, Development of a Semielliptical Partial Ground Plane Antenna for RFID and GSM-900, International Journal of Antennas and Propagation, 2014.

[27] A. P. Duffy, A. Orlandi and G. Zhang, Review of the Feature Selective Validation Method (FSV). Part ITheory, IEEE Transactions on Electromagnetic Compatibility, vol. 60, pp. $814-821,2018$.

[28] A. Duffy, A. Martin, G. Antonini, A. Orlandi and C. Ritota, The feature selective validation (FSV) method, International Symposium on Electromagnetic Compatibility, pp. 272-277, 2005.

[29] Y. G. Rabobason, G. P. Rigas, S. Swaisaenyakorn, B. Mirkhaydarov, B. Ravelo, M. Shkunov, P. R. Young and N. Benjelloun, Design and synthesis of flexible switching $1 \times 2$ antenna array on Kapton substrate, Eur. Phys. J. Appl. Phys. (EPJAP), vol. 74, no. 3, pp. 1-10, 2016.

[30] Y. G. Rabobason, G. P. Rigas, S. Swaisaenyakorn, B. Mirkhaydarov, B. Ravelo, M. Shkunov, P. R. Young and N. Benjelloun, Design of flexible passive antenna array on Kapton substrate, Progress in Electromagnetics Research (PIER) C, vol. 63, pp. 105117,2016 